\title{
REGENERAÇÃO VEGETATIVA: UM ENSAIO SOBRE RELAÇÕES DE GÊNERO
}

\author{
Marilyn Strathern ${ }^{1}$
}

${ }^{1}$ University of Cambridge, United Kingdom

O ano de 2008 testemunhou o funeral de uma jovem garota das Ilhas Trobriand, cujo corpo decorado foi depositado nas pernas estendidas de uma senhora, na mesma posição fotografada por Malinowski há mais de 90 anos. Mosko (2017:264), levado por seus dados a questionar a forma com que Malinowski minimizara a presença dos espíritos ancestrais (baloma) na vida social, se surpreendeu com um detalhe. As mulheres cobriram suas pernas com uma grande esteira; a razão para isso era que, como cristãs modernas, seria impróprio que tivessem qualquer conexão com os baloma. Isso confirmou a especulação de Mosko: quando carregavam os corpos em seus colos, as mulheres estavam permitindo que o ser em decomposição ingressasse nelas, retornando então para um local ancestral, o qual elas incorporavam e de onde capacidades futuras viriam novamente. Vapores potentes deveriam entrar nos ventres femininos. ${ }^{1}$ De outras formas, no entanto, o cadáver estava fechado. O que estava se deformando, como Mosko e seus coautores trobriandeses colocaram, era a aparência corpórea da pessoa: as mulheres tomavam de volta a imagem, os atributos outrora animados da falecida, incorporando-os. Enquanto os laços generativos são traçados através da mãe, a aparência de alguém - Lepani (2012:67-9) enfatiza este ponto - vem de seu pai, ${ }^{2}$ e aquelas carregando a garota eram "irmãs do pai", mulheres da coletividade de parentes paternos ("subclã"). Letal aos parentes maternos, os vapores corporais não as ameaçavam.

É um truísmo que vida e morte sejam entrelaçadas. A etnografia melanésia está repleta de exemplos explícitos a respeito. De fato, na Papua Nova Guiné contemporânea, funerais emergem como se reunissem aspectos de outras práticas, agora deixadas de lado. Mas o que está morto? "Carregar o cadáver" é o momento em que o funeral trobriandês se dedica a uma parte específica de quem outrora esteve vivo, pois a forma corporal de uma 
pessoa reflete a capacidade ou o poder nutriz que deverá retornar à sua fonte regenerativa. A especificidade dos parentes que agem como conduítes é marcada pelo gênero: as carregadoras são mulheres (não homens) e parentes do lado paterno (e não materno) da pessoa falecida. ${ }^{3}$ Por contraste, parentes maternos devem cortar as relações anteriores em que a pessoa falecida estava envolvida, incluindo aquelas com sua parentela paterna, de modo a purificar seu próprio caráter ancestral; a própria capacidade de incorporar sua ancestralidade retornará para a fonte do espírito de seu subclã particular. ${ }^{4}$ A absorção e o corte redistribuem os elementos da pessoa em antecipação a futuras combinações, de novas vidas em novos lugares.

Trata-se de um exemplo potente do que significa ser movido pelos outros, que Butler e Athanasiou (2013) discutem na linguagem euroamericana da apropriação e desapropriação. Identificando uma dupla valência para a desapropriação, envolvendo tanto a exclusão privativa como as modificações da pessoa através da relacionalidade e, portanto, as formas de proibição e desejo que afetam sujeitos que "têm" identidades e corpos, elas nos recordam do vocabulário geralmente possessivo de gênero ("meu" gênero). A partir disso, dentre outras coisas, flui o trabalho imaginativo da reconfiguração queer; parafraseando, o gênero de alguém nunca é apenas seu. Elas são claras sobre o pensamento proprietário que compele tal trabalho e os modos de transformação - como transgênero - que essa matriz permite. Minha própria tentativa (1988) de escrever em termos de uma matriz não proprietária, e as transformações analíticas que isto permitiu, tomou como ponto de partida as preocupações melanésias com transações ("dádiva"). Recentemente, mesmo que de forma pouco original, pareceu-me que o gênero da vida vegetal, particularmente os cultivares, ofereciam algumas possibilidades para a comparação (Strathern 2017, 2019a). Em sua discussão sobre o cultivo de plantas neotropicais, Carneiro da Cunha (2019) explicitamente repudia a propriedade; aqui, no aprendizado sobre as plantas, volto-me ao que também podemos aprender com elas. A questão por trás deste artigo é onde o gênero botânico pode tomar a forma de relações de gênero. Para isso, começo com um diálogo experimental com certos materiais ameríndios.

\section{Genitores e crianças}

"A morte traz a regeneração da vida", notou Rival (2001:69) em sua discussão sobre sementes e clones. ${ }^{5}$ Ela está se referindo às orientações paralelas que os Macuxi adotam ao plantar talos de mandioca (ramas) e ao enterrar cadáveres. Qualquer talo com potencial de sobrevivência e 
perpetuação é plantado, e não surpreende que raízes comestíveis emergentes sejam chamadas de "filhas". De fato, relações entre genitores e crianças ${ }^{6}$ florescem igualmente nas roças da Amazônia e da Melanésia.

Apesar de existir um longo registro de pessoas vivendo junto a uma imensidão de plantas, eu me concentro naquelas cultivadas para serem comidas e cultivadas novamente. Amazônia e Melanésia são locais de antigas culturas de espécies comestíveis. ${ }^{7}$ A propagação ameríndia por meio de sementes (favas, amendoins, abóboras, milho) acompanha a propagação vegetativa através dos talos ("culturas de raízes", como mandioca, aipim, inhame, taro, batatas), ao passo que os principais cultivares melanésios (inhame, taro, banana, cana) ${ }^{8}$ eram - até introduções recentes - propagados apenas vegetativamente. É interessante que, mesmo quando estas culturas podiam ser semeadas, a propagação por meio dos talos era uma preferência marcada ao longo da antiga Melanésia e, parece, em algumas partes da Amazônia (Denham 2017:41; Fausto \& Neves 2018:1613). Rival se dedica a expor a divisão macuxi da mandioca brava entre plantas apropriadas para serem replantadas para a alimentação e aquelas versões autossemeadas, não comestíveis (um tipo que pode se tornar comestível através da propagação vegetativa ao longo do tempo). Apenas o primeiro tipo produz "filhos". Da mesma forma, só "o cultivo de mandioca propagado através dos talos, que reproduz não somente a planta original, mas a multiplica e produz pequenas crianças, está conectado à figura regenerativa da mãe" (Rival 2001:73).

Ao longo da Amazônia indígena, Carneiro da Cunha (2019:132) observa: "plantas cultivadas têm seus próprios desejos e exigem ser paparicadas". Espécies comestíveis devem ser tratadas como filhas, escreve Miller (2019) sobre os Canela. Os pais devem satisfazer os apetites das crianças, sejam elas plantas ou humanos; cuidado, nutrição e sedução têm lugar. As plantas alimentícias jarawara são tratadas como prole, e os espíritos de pessoas e plantas possuem vidas póstumas, em que ativam suas relações (Maizza 2017). Aqueles que paparicam as crianças-planta podem ser homens ou mulheres. Ou, então, o vínculo entre cultivador e planta é especificamente materno, como no caso clássico dos Achuar (Descola 1994; Taylor 2001), e/ou estar invariavelmente em tensão com aquele vínculo entre os donos dos espíritos e suas plantas (ver Fausto \& Neves 2018 sobre os Waiãpi). Comparativamente, os melanésios receiam que suas plantações se afastem dos agricultores descuidados (Kaulong: Goodale 1995), pois sabem que as plantas apreciam atenção íntima (Abelam: Coupaye 2013) e frequentemente as tratam como filhas (Ömie: Rohatynskye 2004). Horticultores podem ser chamados de mãe ou pai (Trobriand: Mosko 2009) e a horticultura pode ser dirigida por especialistas rituais, sob o olhar vigilante dos ancestrais (South Pentecost: Jolly 2001). 
O que é desconcertante em uma lista como esta é o inevitável desprendimento de alguns exemplos de seus contextos regionais ou conceituais, dadas as vastas literaturas sobre a Amazônia e sobre a Melanésia. E há, também, a linguagem indeterminada. Para o primeiro ponto, peço a benevolência da leitora. Contudo, se estou escolhendo um caminho idiossincrático através de diferentes paradigmas e teorizações, bem como por diversos tempos e lugares, é justamente para focar na última questão. O problema foi colocado no começo: uma forma de se entender a "mãe" trobriandesa é considerar a "irmã do pai" e, portanto, considerar o ponto de vista que indica seus gêneros. ${ }^{9}$ Como, então, se pode falar de mães (ou pais) no abstrato, como se fossem genéricos cotidianos, e ainda mais caso se use o termo em inglês sem gênero, genitor [parent]? Quando um termo genérico (como "criança" [child]) significa a ausência de gênero e quando serve como glosa para um duplo sujeito (filhas e filhos)? Onde "mãe" / "pai" são mais bem traduzidos indiferentemente, como "dono" [owner] sugere, ${ }^{10}$ e onde a diferenciação é pretendida? E como qualquer um destes termos se torna parte da análise etnográfica? Indagar de quem as crianças-planta são filhas pode ser um bom lugar para começar.

De suas perspectivas vegetais, as considerações de Maizza e de Miller sobre inflexões de gênero oferecem tal lugar, tanto para as relações de humanos quanto de plantas. Assim, Maizza (2017:206) tenciona o parentesco jarawara - incluindo os cultivares - para elucidar questões sobre "paternidade, maternidade e o papel desempenhado por homens e mulheres em suas formações". Eu tomo estes dois trabalhos, além do de Rival (e, posteriormente, o de Taylor), como fontes etnográficas. ${ }^{11}$ Algumas das relações analítico-etnográficas que eles levantam serão então investigadas a partir de uma seleção de materiais da Melanésia. Mesmo que estes sejam igualmente truncados, espero que possam ser tão esclarecedores quanto os amazônicos. Enfim, reconsidero como certas possibilidades conceituais de descrição antropológica se abrem a partir das formas de vida das plantas.

\section{Qualificações amazônicas}

Plant Kin [Parentesco Vegetal] é o título do livro de Miller. É durante o crescimento no solo que as plantações são protegidas e cuidadas enquanto crianças, e os Canela, de fato, consideram essa relação concluída no momento da colheita (eles se veem comendo adultos cujas vidas terminaram). ${ }^{12}$ A posição recíproca, mãe / pai, também é referida ao dono da roça; sejam homens ou mulheres, tais pessoas são "mães / pais tanto de crianças humanas como vegetais" (2019:112). Por contraste - Miller (2019:199) afirma que elas 
não são modeladas nos laços entre genitores e crianças -, quando se trata de relações com xamãs, os espíritos-mestre, cujo desejo é ver a plantação feliz, estabelecem formas de amizade e sedução, com diferenciação de gênero, a depender de serem Homens Plantas ou Mulheres Plantas. Isto demonstra que, apesar de ser possível falar de mães ou pais das hortas, para os Canela não parece haver diferenças acentuadas entre homens e mulheres. "Genitor" [parent] emerge como um termo genérico apropriado para os humanos que alimentam e zelam pelo bem-estar de suas crianças, encantando suas plantas para mantê-las em seus jardins.

A alimentação e o cuidado exercidos pelos genitores canela se estendem à vida embrionária das plantas comestíveis. Aqui as imagens são as dos cuidados durante a gravidez, com referência específica às mães: "semelhante à atenção a um feto em um útero, as mulheres são as principais zeladoras das sementes e dos talos durante esse período de espera" (2019:160). (Na distribuição das tarefas da roça, as mulheres plantam as sementes infantis no solo). No geral, tais cuidados parecem ser atividades dos vivos. Pais falecidos (sejam homens ou mulheres) se transformam em seres cujo estímulo benigno não pode ser tomado como dado. Os espíritos dos mortos podem ser encontrados nas roças, ora trazendo colheitas surpreendentemente abundantes, ora tomando para si as crianças humanas; convertidos em vegetais cultivados, espíritos humanos podem habitar o corpo outrora sem alma das plantas, e as crianças humanas e as crianças plantas não mais florescem em paralelo.

A única plantação aparentemente com gênero em que Miller (2018:115) se debruça é a mandioca, com a mandioca brava possuindo atributos "masculinos" e a mandioca doce, atributos "femininos" (há duas variedades intermediárias), que informam seus encontros com os horticultores. Mandioca brava, a comida "verdadeira" dos Macuxi, é o foco do trabalho de Rival (2001). Ela oferece um espectro de respostas para a questão: filhosplanta para quem? Há muitas formas pelas quais alguém pode se apresentar como pai / mãe: "a relação pais-filhos de criação e proteção entre cultivadores e mandiocas; a relação de adoção espiritual, que também é uma relação pais-filhos e mestre / dono-seguidores; a relação entre a Mãe Mandioca e as plantas mandioca; e, finalmente, a relação amplamente não especificada de cooperação amistosa entre Mãe Mandioca e os cultivadores macuxi". Esta última articulação com a Mãe Mandioca exige que os "humanos [...] protejam e nutram suas crianças" $(2001: 74,69)$. No entanto, os exemplos começam com a relação que ela acha mais interessante. Apenas aplicável à mandioca, os talos plantados e as raízes comestíveis formam entidades distintas, e como "mãe" e "filhos" um talo e suas raízes existem em uma relação de potencial diferença. ${ }^{13}$ 
A vida inerente à rama de mandioca parece específica ao horticultor, ao menos na medida em que os talos distribuídos devem ser despidos de qualquer coisa (folhas, pedaços de raiz) que evoquem a potência do horticultor anterior; ao mesmo tempo, a vida da safra, como um todo, deve prosseguir, sendo replantada. Contudo, "filhos" mandioca nunca crescem a ponto de se tornarem "pais", Rival indica (2001:75). O destino das raízes é serem comidas. O poder de procriação, então, reside nos talos, que parecem dimórficos em termos de gênero, dependendo de o ponto de vista sobre a planta ser o de sua capacidade genitora ou o da substância que ela emite. "Apesar de a rama ser considerada como mãe, posto que ela carrega suas raízes filhas, estas são também o produto de uma agência paterna, a seiva, que é análoga ao leite e, como o leite, deriva do sêmen, a substância masculina quintessencial" (2001:73). ${ }^{14}$ De maneira semelhante, como os "cultivadores macuxi formam pares conjugais, eles se tornam sínteses transformativas dinâmicas, adotando mais de uma qualidade ou atributo" (2001:77). Então ativados, podemos dizer, o casal internamente gendrificado atualiza uma relação de diferença. Como seres não procriadores, então, seria importante que as raízes fossem comidas como "crianças" não diferenciadas [por gênero]?

Onde o estudo de Miller elucida a natureza multifacetada do cuidado, o trabalho de Rival põe em primeiro plano as relações generativas e procriadoras; por sua vez, as considerações de Maizza se baseiam nas distinções jarawara entre pais "reais" e de "criação". Pais reais são aqueles que dão à luz aos filhos, pelos quais podem ou não ser os principais responsáveis; a procriação não é o foco dessas relações. Pelo contrário, "toda maternidade / paternidade é uma forma de sedução" e, de fato, se a "maternidade / paternidade jarawara não é diretamente ligada à reprodução sexual", tampouco o é à sexualidade (2017:210). ${ }^{15}$ As crianças se permitem seduzir por vários parentes de acordo com promessas de cuidado, uma persuasão também exercida pelos pais reais. Considere-se, então, o parentesco das plantas e o parentesco das pessoas com elas. As plantas jarawara possuem espíritos (duplos, sujeitos potenciais) que saem da planta em crescimento assim que ela esteja bem acima do solo. Os xamãs dizem que o espírito de uma planta é sua criança, que abandona seu corpo chorando, em um processo que "se assemelha ao nascimento (ou à morte)" (2017:211). No estrato superior, tais crianças-planta são cuidadas pelas pessoas-planta ${ }^{16}$ que se tornam seus pais de criação, enquanto os horticultores permanecem sendo seus pais reais e, portanto, pais reais das plantas em suas roças. Casados ou não, os pais de criação de uma criança humana são, frequentemente, irmãos de seus pais reais. Semelhantemente, 
os pais de criação das crianças-planta no estrato superior são, comumente, irmãos-planta dos pais reais (humanos), ou seja, Maizza observa, filhosplanta dos pais dos pais humanos.

Ao focar na socialidade da sedução que permite aos Jarawara criar os filhos e viver juntos enquanto, inevitavelmente, os abre às tentações dos seres predatórios (a abdução dos espíritos sendo um risco constante), Maizza também descreve quão importante as almas das crianças-planta são para a habilidade do xamã de viajar. Uma capacidade semelhante à mobilidade xamânica é evidenciada em um tipo específico de agência feminina: a habilidade das mulheres de serem facilmente persuadidas. Este acaba por ser um ponto importante - dos relatos em que me baseio -, em que a exegese chega à diferenciação de gênero. Se "ser humano" é mais bem entendido como "tornar-se planta" (2017:213), a vida parece ser descrita considerando a presença dos espíritos: em suas roças, as pessoas (com espíritos) estão cultivando os espíritos das crianças-planta que irão, na morte, conduzir os seus ao alto, pois sem as suas próprias crianças-planta o espírito do morto não pode escapar à encarnação terrena. Questiona-se se os horticultores procuram, ou encontram, em suas plantações a particular capacidade das mulheres de serem persuadidas. ${ }^{17}$

A extensão em que diversas relações entre pais e filhos são inevitavelmente qualificadas de acordo com interesses analítico-etnográficos específicos oferece um contexto em que se pode ganhar algum sentido sobre onde a especificidade de gênero entra e sai de cena, como na diferenciação masculino-feminino. Ênfases distintas emergem de vasto material melanésio.

\section{Qualificações melanésias}

A investigação de Rival sobre a mandioca brava faz uma reveladora referência aos Nakanai da Melanésia (a partir de Yamaji 1994). Onde os Nakanai compreendem que as "sementes"18 e os brotos são filhos da planta mãe, os Macuxi insistem que são as raízes (comestíveis) da mandioca que são filhas das ramas mães. Também os "talos plantados regeneram ramas (i.e., mais talos)"; ainda assim, tais ramas não são consideradas aparentadas com nenhum talo genitor (Rival 2001:70). Contudo, se uma planta e sua progênie são frequentemente vistas dessa forma na Melanésia, o idioma da relação não é exaurido pela "consanguinidade" que interessa a Rival; assim como ela mostra que existe mais do que se vê na rama de mandioca, dada a sua capacidade procriadora, há mais na evocação melanésia da mãe (ou do pai) e da criança. É a ruptura entre elas que eventualmente conta. 
Desenvolveremos este ponto adiante. Enquanto isso, o que é plantado é (um pouco de) o próprio elemento comestível, o que lança uma interrogação adicional à relação mãe/pai-criança. Isto é particularmente verdadeiro para o inhame e o taro, fundamentais e icônicos na antiga Melanésia. ${ }^{19}$

O inglês genérico, criança [child], engloba o sentido de ser jovem e ser descendente (independente da geração) de um genitor. Como uma dupla referência no uso nas Ilhas Trobriand, aparecem dois termos para se referir à prole. No relato de Mosko (2009), indicam-se as frutas que as pontas das plantas produzem; outro uso é no termo de parentesco "criança", a respeito de filhas e filhos. ${ }^{20}$ Um horticultor do desejado inhame diminuto é o "pai" das crianças-inhame e sua esposa é delas a "mãe". Ou os inhames podem ser chamados de crianças da roça, quando o solo já estiver preparado por seu dono masculino (e mágico da roça) e se engravidar da plantação crescente. Em relação a seu subclã, o útero da mulher se recorda da terra dos mortos da qual as crianças-espírito vêm, sua forma aqui sendo a da terra da roça. Por outro lado, a propagação e a morte humanas remetem às dos inhames, em que as partes crescentes iniciais têm diferentes destinos (meus termos). Tanto as pontas das raízes sob a superfície como a folhagem acima dela possuem "olhos" - como há "olhos" em cada parte do tronco do corpo de uma pessoa - que crescem se afastando da base do velho tubérculo (que está morrendo) de que brotaram. Subsequentemente, a própria folhagem murcha no momento em que o corpo do novo tubérculo, inchando desde as raízes, torna-se maduro para a colheita. Assim, quando a extremidade da folhagem morre, seu fruto subterrâneo se solta. Agora as plantas foram podadas para se diferenciar o destino das filhas (tubérculos "femininos" a serem replantados) daquele dos filhos ("masculinos", para alimentação e dádiva) (2009:686). Conquanto estes últimos não possam regenerar mais inhames, eles sustentam os corpos das pessoas por outros meios. ${ }^{21}$ Convertidos em riqueza tanto feminina quanto masculina, eles também habilitam os poderes das pessoas de serem reconhecidas, concebidos como o produto final ou a extremidade que, na morte, irá gerar frutos, como a fama. Assim, as crianças são os frutos das extremidades (genitais) de seus genitores, com pais e mães formando a base ou a causa das crianças. Mosko (2009:696, ênfase omitida) comenta sobre a "bifurcação das agências de homens e mulheres em termos do fruto específico que produzem... a agência feminina na criação de fama e a masculina na procriação de crianças... são, como fruto, comparativamente breves, ao passo que a agência dos homens na produção de fama e a agência das mulheres na reprodução de crianças são relativamente duradouras". Em termos de gênero, a repetida bifurcação em masculino e feminino aponta para diferentes possibilidades temporais. 
O inhame aparece, então, em outra forma que não planta (como riqueza, por exemplo), mas com ecos da mesma morfologia; doravante, fases de "crescimento pessoal" correspondem "à base, corpo, extremidade e fruto [na morte] da vida completa da pessoa" (2009:693). Para o presente propósito, limito o foco a fim de considerar um aspecto do cultivo que a divisão de inhames inteiros entre aqueles para se plantar e aqueles para dar ou comer possivelmente obscurece. Com outros cultivares, e em alguns lugares como uma alternativa aos inhames inteiros, a parte plantada precisa ser separada daquela consumida. A descrição de Malinowski sobre o cultivo trobriandês do taro é precisa. O taro é colhido com seu talo ou rama folhada junto ao cormo; então, a maioria do cormo é fatiada, separando-a do talo, resultando em uma grande porção destinada à alimentação, enquanto o talo aparado, ainda com uma pequena seção do cormo, será replantado. ${ }^{22}$ Como disseram a Malinowski (1935b:105), "a superfície do corte [entre os dois é onde]... se inicia o processo de crescimento", com um novo taro eventualmente suplantando a seção inicial, que (lhe disseram) apodrece, seus restos sendo descartados como "pós-parto".

Goodale (1995) está entre os vários melanesianistas que conectaram as sugestivas características da reprodução vegetativa a como as pessoas pensam sobre a sucessão de pessoas. Os Kaulong, cuja plantação principal é o taro, tratam o talo (cortado, com o fragmento do cormo aderente) como intrinsicamente valioso. Enquanto os cormos do taro precisam ser persuadidos a crescer e ser protegidos de raptos durante suas perambulações noturnas, as pessoas ajudam os talos colhidos a viajar. ${ }^{23}$ Talos são "herdados, trocados, importados e exportados", então mesmo que um talo precise ser plantado em até três dias após a colheita, ele perpetua uma história duradoura, seu signo de "imortalidade" (1995:77). Um horticultor pode se referir à planta como sendo a de seu avô, não apenas como sendo a mesma variedade de taro que seu avô estimava, mas como sendo a mesma planta. Em outras palavras, independente de quantas vezes seja plantado, o mesmo taro está se repondo.

Os ritmos temporais da reposição entre os Kaulong impõem uma divisão radical entre o antes e o depois do matrimônio; o matrimônio é explicitamente para procriação, e entre os Kaulong antigos era o ambiente exclusivo das relações sexuais. Então a divisão era - e (no horizonte etnográfico dos anos 1970) em larga medida permanece - entre os sexualmente ativos e os inativos, uma divisão ainda maior (Goodale afirma) que a distinção categórica entre homens e mulheres. A ênfase está na paridade cotidiana entre irmãos, e em relações geralmente livres e simples entre homens e mulheres. Ao mesmo tempo, o casal conjugal começa a se isolar e, então, de 
diversas maneiras (observando tabus, morando fora da aldeia), se separa do corpo dos solteiros. O ato sexual é visto como uma atividade extremamente vergonhosa, necessária apenas e precisamente porque cada cônjuge procura o seu substituto. A principal relação em questão não é a aquela entre marido e esposa, ou a da linha de um cônjuge sobre o outro, mas a relação entre irmão e irmã. ${ }^{24}$ Goodale (1995:138, ênfase omitida) argumenta que os "Kaulong evitam a vergonha da sexualidade buscando uma situação em que irmãos cruzados assexuais se repõem como um conjunto de irmãos, negando implicitamente a reprodução sexual". Este é, ao menos, o modelo dos homens, e é "baseado em reprodução aparentemente assexuada da vida de plantas tropicais, em que novas gerações são clonadas a partir das antigas sem contato sexual" (1995:158). Mesmo que os Kaulong sustentem que a morte sucede a atividade sexual para ambos os cônjuges - uma vez que as crianças nasçam, "a imortalidade é alcançada, a morte pode ocorrer" - são particularmente os homens que têm medo de manter relações sexuais. ${ }^{25}$ A mulher toma a iniciativa; os homens casam tardia e relutantemente, em face do inevitável declínio e apodrecimento seguintes. Nova vida surge, é claro, não do talo do taro, mas do fragmento do cormo em anexo, destinado à decadência junto à velha rama.

Ao longo das gerações, os Kaulong podem se suceder em linhas de mesmo sexo, embora um filho também possa ser considerado o substituto pessoal de sua mãe e, uma filha, a de seu pai. Os Ömie, conhecidos por seu sistema incomum de "afiliação sexual", dão especial atenção ao gênero da criança. ${ }^{26}$ "A substância do genitor causa a existência da criança" (Rohatynskyj 1990:439): doravante, uma garota assume o emblema vegetal de sua mãe porque - os Ömie dizem - ela tem o corpo da mãe, assim como um rapaz toma o emblema de seu pai. ${ }^{27}$ Rohatynskyj (2004:77) interpreta essas filiações em termos de "crenças na partenogênese por parte de pessoas de gênero neutro, tanto homens quanto mulheres sendo capazes de reproduzir a si mesmos". A partir de Rival (1998) e Bonnemère (1998), Rohatynskyj se alonga nas elaboradas analogias que os Ömie estabelecem entre o ciclo de vida de crescimento de homens e mulheres e aquele da ramificação e frutificação das árvores. Dentre os cultivares, destacam o inhame: espíritos se manifestam em seu crescimento subterrâneo. As mulheres recebem inhames de suas mães para plantarem na terra de seus maridos, uma transmissão de mesmo sexo de uma linha de plantas passadas de mãe para filha por várias gerações. Os homens plantam sua própria linha de inhames, longe das mulheres, com inhames longos especiais sendo objetos de ornamentação e ostentação. Os homens ömie envolvidos na reconstrução de antigos rituais de iniciação masculinos, para o interesse da etnógrafa, identificam os noviços 
como simultaneamente espíritos dos mortos, fetos no útero e bebês calaus ${ }^{28}$ no ninho, observando a necessidade de desenvolver os jovens às escondidas (no subsolo), como os inhames crescem.

Dois elementos emergem. Primeiro, Rohatynskyj explicitamente advoga pelo alargamento do alcance da análise com fins de incluir o que é convencionalmente (e, à luz deste material, ironicamente) chamado de mundo não humano. Uma matriz de conexões com a terra e outros seres, incluindo plantas (em que os emblemas vegetais são apenas um exemplo), "descentra a fisiologia humana como a moeda da diferenciação de gênero e identifica as distinções de gênero como 'emanando das relações que as pessoas estabelecem com o ambiente não humano' (Bamford 1998:46)" (2004:77). É aqui que ela localiza sua discussão sobre reprodução de mesmo sexo. Segundo, a observação aparentemente banal de que inhames são tratados como crianças é colocada ao lado de sua identidade como espíritos; na condição de espíritos ancestrais indiferenciados, os inhames possuem uma ativa vida subterrânea, que inclui a visita a amigos em outras roças. Seja na manifestação enquanto espírito dos mortos ou do mato, sabemos que, ao menos para os rapazes, o ingresso na iniciação é uma morte a ser seguida por um "renascimento na forma da geração ancestral de seus avós" (Rohatynskyj 2004:90). Onde regras sexuais específicas como as dos Ömie "excluem o interesse de um genitor no produto da atividade de procriação, a criança replica não o relacionamento de seus pais, mas um 'nexo social mínimo das relações sociais que são, em parte, responsáveis pela gênese social do próprio genitor'" (1990:437). Resumindo, a criança emerge como o genitor de seu genitor. ${ }^{29}$

Os alinhamentos de gênero ömie colocam em relevo uma dupla (mas não equivalente) generatividade na noção melanésia de reposição. Genitores são substituídos por suas crianças e avós por netos (irmãos por irmãos, entre os Kaulong). Mesmo assim, a sucessão genitor-criança parece acarretar a morte antes do surgimento de nova vida, ao passo que um neto aparentemente surge no lugar de um avô como uma recriação de si próprio. Há numerosas formas de se pensar sobre a interseção desses modos; sugiro que alguns aspectos da vida dos cultivares, particularmente das plantas cultivadas para a alimentação e crescimento, encapsulam ambos.

\section{Proposições e recusas}

Refletindo sobre a propagação vegetativa, como no plantio de fragmentos tuberosos ou setts, ${ }^{30}$ um etnógrafo dos Abelam melanésios emprega uma fórmula assaz curiosa: horticultores de inhame "não pareciam percebê-la 
como um processo assexuado" (Coupaye 2013:140). Trata-se de uma proposição? Trata-se de uma recusa? Até agora, a análise procedeu através da apresentação etnográfica (seleção de detalhe, sequência narrativa, e assim por diante). Agora, faço um movimento analítico de tipo mais especulativo, que deriva de longevas discussões antropológicas sobre gênero e sexo na reprodução, e voltarei, na conclusão, à expressão incomum de Coupaye. O movimento é feito em relação aos materiais melanésios (e seus extensos ambientes etnográficos). Eu hesitaria em sugerir algo comparável para a Amazônia. Isto posto, o estímulo dos poucos trabalhos amazônicos aqui citados deve estar evidente, e guiam a exposição a seguir.

Paternidade / maternidade sem procriação: Maizza deixa claro que, enquanto os parceiros sexuais jarawara (podem ser múltiplos) geram a criança, a paternidade / maternidade persuasiva é outra questão. Esse deslocamento de atributos é um indicador útil. À paternidade / maternidade sem procriação podemos somar outra possibilidade conceitual: procriação sem sexo? Claramente, a linguagem da exposição requer cautela. Ao menos em inglês, caso se coloquem os atributos masculino e feminino juntos em um contexto de procriação, as relações cruzadas inevitavelmente adquirem conotações sexuais. ${ }^{31}$ Maizza (2017:213-4) questiona a ênfase que o pensamento sobre gênero no Ocidente atribui à divisão sexual-procriadora de pessoas, ela mesma questionando sobre o deslocamento da procriação à aliança matrimonial. Mas está no espírito de seu exercício indagar se as referências ao pareamento procriador de elementos masculinos e femininos (de pessoas, ações, substâncias, energias) são axiomaticamente de implicação sexual; isto, por sua vez, levanta a questão sobre onde tal implicação pode ser encontrada. Existem outras formas de se imaginar o que pode haver de sexual na procriação? Como veremos, a propagação vegetativa põe em nosso caminho uma possibilidade para refletirmos sobre ambas as proposições.

Um comentário inicial sobre o termo propagação vegetativa é necessário. Propagação sugere a agência de outro. Sobre os rituais de crescimento ömie, Rohatynskyj (2004:97) argumenta fortemente que as relações manipuladas "não são apenas aquelas entre pessoas, mas também entre corpos humanos e as entidades não humanas que os cercam". Longe de invocar um ambiente inerte para a atividade humana, ela está atentando para as íntimas "relações de identidade e interação com a própria terra e sua vegetação" (2004:97): o nexo de corpo-solo-espírito é simultaneamente material e imaterial. Portanto, a agência humana é simultaneamente a agência ancestral e a agência da terra nutridora. Ao mesmo tempo, podemos dizer, tais percepções sobre a agência também preveem tarefas a serem cumpridas. Nos termos das ações que as pessoas devem tomar, os inhames não geram a si mesmos; como os garotos, precisam ser gerados. 
Procriação sem sexo: os Kaulong insistem em um deslocamento que deve ser resolvido ao longo do tempo. Parceiros sexuais criam suas próprias crianças; os principais objetos de reposição são, ao mesmo tempo, a pessoa individual e, em termos de relações, os irmãos. O conjunto de irmãos é um foco de regeneração particularmente masculino. O sexo é evitado - não negado em abstrato, mas negado por ele. O conjunto em questão, idealmente composto tanto de irmãs quanto de irmãos, é imaginado na terminologia de Goodale como assexual. ${ }^{32}$ "Argumento que a autorreprodução de conjuntos de irmãos cruzados pode ser interpretada como uma recusa cultural de que a atividade sexual é necessária para a vida, para a imortalidade, ou para a regeneração de si. Da mesma forma, o homem unissexual do mundo é uma recusa semelhante. O ideal seria haver homens aptos a se reproduzirem sem o matrimônio, já que eles podem produzir todo o resto que há de valor no mundo" (1995:180-181, ênfase mantida). Então, ela coloca que a distinção de gênero perde importância em comparação com a unidade dos irmãos, preferindo redescrever o próprio modelo (unissexual) como assexual. O relato de Miller sobre os cuidadores canela nos leva a notar que as relações kaulong descritas como assexuais se referem a irmãos homens e mulheres (gêneros cruzados) entre si. Os Kaulong tomam várias medidas para isolar um conjunto de irmãos adultos de qualquer conotação de atividade sexual, a ponto de marginalizarem socialmente os casais conjugais. Um conjunto de "irmãos-cruzados" terá de advir de um par conjugal sexualmente ativo, mas é, ele próprio, inativo a este respeito. Haveria aqui um eco dos "genitores (conjugais)" canela, em que um duo de homem e mulher provê às crianças? Talvez aquela categoria genérica canela, genitor [parent], também tenha uma dimensão assexual: a categoria não é internamente homogênea (mães e pais estão ambos implicados), mas a criação suspende ou coloca em segundo plano a conotação sexual.

Isto nos leva a uma escolha de potencial analítico. Considerando a primeira proposição sobre procriação e sexo, seria a atividade sexual do casal kaulong "procriadora", ou nós deveríamos reservar este conceito ("procriação") para os irmãos assexuais que regeneram a si mesmos? Afinal, os últimos possuem um futuro que os primeiros não têm. ${ }^{33} \mathrm{~A}$ vida das plantas oferece alguns esclarecimentos. Vimos que, nos casos do inhame e do taro, o crescimento novo vem do antigo tubérculo ou cormo; a parte replantada nutre seu substituto e, então, seca e morre. Sua razão de ser é ser substituída. Tomo como uma generalização melanésia que, conforme as crianças crescem, seus pais decaem, esgotados pela prole que lhes toma o lugar; portanto, em um registro corporal, a preocupação é com o declínio. 
As pessoas comentam rotineiramente como o corpo de uma mulher gradualmente encolhe por meio dos partos e como o corpo do homem murcha na medida em que aqueles de suas crianças aumentam. ${ }^{34}$

Com isto em mente, e sem maiores definições sobre quem são os atores, podemos colocar o conceito de procriação na observação geral de que as pessoas são divididas em gerações: aquelas que procriam (a dos genitores) e aquelas que são procriadas (a da prole). ${ }^{35}$ Os primeiros se dirigem rumo à morte, os últimos brotam cheios de vida. Ainda assim, as crianças não podem criar crianças, apenas os genitores podem; posto de melhor maneira, aqueles procriados devem ser tornados procriadores para saírem de um estado desativado para um ativado. Uma vez colhido, o tubérculo ou o cormo para de crescer, mas quando um pedaço dele é cortado (ou quando as partes que serão plantadas são separadas), um novo ponto de crescimento é criado. Essa ativação exige um agente, o horticultor que corta e planta, querendo ajudar não esse tubérculo, mas sim o seu descendente a florescer. Em sua forma mais simples, então, a relação binária entre as gerações é antecipatória: ela observa os frutos que virão da transformação de "crianças" em "genitores". Ela também é recursiva. A recém-criada geração procriadora surge daqueles que deixarão de ser ou que já não são mais procriadores. Portanto, os pais dos pais, potencialmente manifestos na geração dos netos, aparecem não como procriadores, e sim como tendo sido procriados, sendo tão inertes (nesse sentido específico) quanto as crianças.

Enquanto os melanésios podem procurar reposições pessoais para si próprios na geração seguinte, esta noção está presente de maneira ainda mais enfática na percepção de três (ou mais) sucessões geracionais. Geralmente uma preocupação mais masculina que feminina, um coletivo de parentes - ou um grupo local, um local com nome, um conjunto de irmãos - está sempre sendo restaurado em sua forma original ou ideal. Como uma relação de substituição, então, a procriação no sentido de "reposição" não implica, por si só, geração sexual. A clonagem parece uma metáfora óbvia para a procriação assexual. Dado que os melanesianistas costumam fazer referências à clonagem quando tratam de propagação vegetativa (como Coupaye 2013:39; Goodale 1995:180), volto-me para um tópico que também tem sido tema de debate entre os amazonistas. Talvez ilumine onde desejamos colocar a ênfase procriadora.

A descrição anterior das crianças-mandioca macuxi, as raízes que nunca poderão se tornar talos, agora possui um eco melanésio; contudo, sua infertilidade persiste sem a promessa de transformação futura. Como genitores e crianças na Melanésia (falando em termos de procriação), incluindo a noção trobriandesa do "fruto" que é outro em relação àquilo que 
o gera, o talo da mandioca produz algo que ele não é (Rival 2001:75). Aqui a comparação para, pois o talo não tem a possibilidade de ser substituído por seus descendentes. ${ }^{36}$ Rival, portanto, recusa a relevância conceitual da clonagem para essa sequência (ela faz um uso irônico do conceito a propósito dos tipos de mandiocas autossemeadas). Os cultivadores macuxi, ela diz, não estão lidando com réplicas de um original. Antes, lidam com o poder "procriador", "isto é, o poder de criar vida nova, ao invés de apenas replicar a própria vida, que é absolutamente central para a construção da pessoa e a fabricação do corpo" (2001:77). Tal poder de transformação vem dos pares conjugais que os cultivadores formam entre eles mesmos e da procriação internamente diferenciada dos talos de mandioca. Sua análise é parte de uma crítica mais ampla sobre a divisão botânica convencional entre reprodução vegetativa e sexual. Se a clonagem assexual deveria aproximar algumas considerações indígenas sobre replicação, a proposição botânica falha justamente em reconhecer onde as pessoas percebem a sexualidade nas plantas.

Onde isso coloca a noção de "substituição"? Tecer uma narrativa por meio das plantas remove, necessariamente, numerosas dimensões da vida social. Mas sua rigidez chama a atenção para o que pode ser uma ênfase mais melanésia que amazônica, ao menos na medida em que os melanésios refletem sobre a forma com que uma geração suplanta a outra. Uma substituição eclipsa seu próprio antecessor. Por um momento, isto parece remeter à referência de Maizza sobre "tornar-se planta". Uma vez que os seres humanos jarawara tenham se tornado parentes das almas-planta, e para isso ocorrer a morte é necessária, a diferença entre humano e planta é apagada. ${ }^{37}$ Mas onde, como geralmente parece ocorrer na Melanésia, gerações alternadas se fundem, entre gerações adjacentes a morte põe em marcha todos os tipos de diferenciação. Um taro ao mesmo tempo repõe e desloca um taro; mas a substituição é mediada por uma diferenciação absoluta entre o que é comido e o que é plantado. Pode-se dizer que este último estágio, intermediário, é um movimento rumo a "tornar-se indiferenciado"? Para as pessoas, são nessas e através dessas diferenciações intermediárias que muito da vida social parece ocorrer.

Em suas considerações sobre os Achuar Jívaro, Taylor também emprega o conceito de clonagem (de maneira bem distinta da de Rival, como a última nota). Ela fala de uma semelhança engendrada (Taylor 2001:51), modelada na propagação da mandioca, com as canções das mulheres horticultoras identificando-as com uma figura "autoclonada" e "unigênero" que é, para as plantas da roça, mãe, assim como para suas crianças. "Um tipo de clonagem" vale para as filhas em relação às mães, bem como para os filhos em relação 
aos pais. Contudo, a qualificação é significativa. Central para a análise de Taylor é a diferenciação interna da pessoa achuar. Pois os alinhamentos de mesmo gênero acabam sendo apenas um de dois aspectos da pessoa, o outro derivando das relações dos pais com afins e animais. Essas relações tornam as crianças apenas meio iguais aos genitores de mesmo gênero; garotos são também meio afins e, portanto, inimigos; garotas são meio animais ou "presas" (2001:51). Talvez tal diferenciação interna possa ser traduzida na diferenciação de gerações da Melanésia, ${ }^{38}$ como os habitantes das Ilhas Trobriand tornam explícito em suas reconstruções post mortem da pessoa falecida. "Reposição" simultaneamente remete a uma semelhança, ou à ideia de réplica, e a outro horizonte, um novo tempo, uma revigorada rede de relações para o corpo regenerado.

De fato, certas consequências dessas equivalências jívaro produzem situações sociais que parecem obscurecer as realidades melanésias. Taylor escreve, por exemplo, sobre uma suspensão de paternidade ou maternidade por parte dos pais, essas capacidades sendo ativadas apenas no casamento de um dos filhos, através da aquisição de afins em termos amazônicos. Para aquelas sociedades melanésias onde a capacidade procriadora é inaugurada com a iniciação para os rapazes ou com o preço da noiva para as garotas, a separação de um filho de sua mãe ou de uma filha de seu pai antecipa a paternidade do rapaz ou a maternidade da moça - e assim traz à tona a generatividade da geração mais velha. Os idiomas de ruptura e corte invariavelmente acompanham tanto a iniciação como o preço da noiva. Desse modo, argumentou-se para os Gawigl (Schneider 2017) que o pai da noiva se torna pai da noiva no momento em que sua filha - agora visivelmente com gênero cruzado - se separa dele no casamento.

Uma observação adicional. Em seu capítulo, Taylor não afirma que a clonagem jívaro que ela descreve, modelada no cultivo de mandioca, é assexual (e, na verdade, nem precisaria fazê-lo). ${ }^{39}$ Isto indica uma forma de se abordar a segunda proposição: pensar além da procriação sem sexo, observando o que, independentemente das referências explícitas à atividade sexual humana, pode ser "sexual" no processo de procriação.

\section{À guisa de conclusão}

Lembremo-nos daquela curiosa fórmula oferecida pelos produtores de inhame que não pareciam perceber a propagação vegetativa como um processo assexuado. Eles não a percebiam como não sexual. Foi com um dos argumentos de Butler (2000) em mente que questionei se seria uma proposição ou uma recusa. No centro de suas reconsiderações sobre 
o parentesco, na figura da Antígona de Sófocles, está a implicação do enterro proibido / atraente do corpo de um irmão. Antígona não afirma, mas igualmente não nega o seu ato: "ela se recusa a negar" que o fez.

Descrevi como as ambiguidades e as complexidades sobre o que é substituído na geração procriação-morte, com todos os seus ônus sociais, expectativas relacionais, múltiplos débitos, redes de troca e assim por diante, se tornam radicalmente simplificadas na presença de uma terceira geração, aquela dos parentes ancestrais e progênie futura (ou de qualquer forma que a relação fundida seja considerada). Com a última, a reposição parece autoevidente. Mas tal reposição só seria assexual se aquelas diferenciações intermediárias fossem ignoradas. Reviso minha linguagem. Prefiro não negar que o processo de reposição seja sexual. E isto também vale para a propagação vegetativa. Uma nova raiz de inhame, ou cormo de taro, pode ser tomada como o mesmo que aquilo que repõe, mas ela existe em um novo presente, pois o retorno de uma geração anterior também implica que ela precisa ser renovada. Como vimos, não haverá inhame ou taro sem a intervenção do horticultor, seja ela mágica ou não; permaneço apenas em uma intervenção, que aponta para um momento binário englobante, com implicações para as ações das pessoas. ${ }^{40}$ Alguém corta o fragmento gerador (e eu torno a afirmação tão mundana quanto possível). Esta intervenção é, simultaneamente, causa de morte e produtora de vida. Neste sentido, a ação de cortar os talos é, em si mesma, um ato procriador. ${ }^{41}$ É certamente um ato mortal. Prefiro não negar que também seja um ato sexual.

No que diz respeito às pessoas, uma perspectiva particular sobre a formulação das relações de gênero perpassa estas considerações, tomadas dos materiais melanésios e de seus guias amazônicos: masculino e feminino não estão em um estado de perpétua (sexualmente definida) diferenciação. Enquanto genitores moribundos seguem rumo a uma ancestralidade indiferenciada, a relação entre eles deixa de ser geradora. Correlativamente, na produção dos genitores, a atuação dos estados de gênero cruzado em relação aos outros também implica um contraste, alternando temporalmente entre os seres procriadores ativos e (neste sentido) os seres não procriadores inertes. Contudo, mesmo que uma antropóloga possa escrever sobre os modelos dessa maneira, um idioma mais apropriado pode nos convidar a pensar sobre gerações cortadas, uma a partir da outra. A separação entre genitores e crianças deve ser repetida diversas vezes; não há regeneração sem destacamento. Assim também para os genitores em relação aos seus próprios genitores. Todavia, ao invés de um corte duplo, o novo corte parece cancelar (repor, substituir) o antigo. Se assim for, então entre avós e netos não parece haver corte e, neste sentido, tampouco há diferença geracional. ${ }^{42}$ 
Mesmo que uma geração parta de um corte na anterior, o resultado não é uma acumulação serial de gerações. Antes, há duas metades: procriadores (genitores, pais) e procriados ou aqueles que procriaram (crianças, avós). Relações de gerações cruzadas aparentam ser ativadas de forma tão intermitente quanto as relações de gêneros cruzados.

É aqui que os extremos ${ }^{43}$ das ambições procriadoras dos homens, entre os Kaulong antigos, são iluminadoras. É como se o estado de indiferenciação que usualmente emerge em três gerações pudesse ser estabelecido em duas. ${ }^{44}$ A recusa da reprodução sexual na reposição de conjuntos de irmãos era, podemos argumentar, uma recusa que explicitamente colocava o ônus procriador na morte. Na leitura de Butler da irmã sofocliana, vida e morte estavam em um relacionamento fixo; o irmão de Antígona estava irremediavelmente morto. Pelo contrário, no passado, uma irmã kaulong quase inevitavelmente se vê tendo de trabalhar na vida que a morte traria. Quando um marido morria, sua viúva mantinha vigília ao lado de seu túmulo, sendo então estrangulada ao alvorecer por um irmão - ou, no lugar de seu irmão, por um filho - antes de ser enterrada com seu esposo. O motivo parece leve demais para o horror evidente causado àqueles que tinham de cometê-lo: a esposa estava acompanhando seu marido ao próximo mundo. O ponto era que o casamento estava sendo expedido intacto, os pais sendo substituídos simultaneamente. Isto cumpria um ideal, apesar de assimetricamente ${ }^{45}$ sobre como, em seus filhos, um novo conjunto de irmãos se realizaria enquanto uma entidade completa, pois nada mais nasceria nela. Com o vínculo sexual entre os pais dos irmãos substituído no momento da morte, infiro que o irmão matar sua irmã simultaneamente dissolve (ou inicia a dissolução) seu próprio conjunto de irmãos em benefício da próxima geração.

Aparentemente, a viúva kaulong pode precisar incitar seu hesitante carrasco a levar a cabo o ato, até mesmo envergonhando-o para que o faça, ecoando o vigoroso protesto da relutância masculina em ingressar nas relações sexuais que pressagiam seu declínio. ${ }^{46}$ Assim, a irmã tinha a lida de tornar a morte (do casal) completa para efetivar a geração seguinte que, por sua vez, buscará seus próprios substitutos. ${ }^{47}$ Ativar a diferenciação de gênero cruzado entre a irmã e o irmão também criava o divisor geracional, doravante possibilitando uma nova (re)concepção da próxima geração de irmãos de gêneros cruzados. Esse divisor, especulo, inseria uma momentânea, mas, ainda assim, interveniente "geração" (na pessoa do executor e no suicídio [meus termos]) entre as duas. Podemos concluir que esta morte encenada era, de fato, um ato procriador e, mais ainda, um ato não sexual - no sentido sugerido pela propagação vegetativa dos cultivares. 
Entre as escolhas analíticas abertas à exposição antropológica, os termos gerais "reprodução" ou "regeneração" se sustentam em diversos registros; talvez "procriação" exija atenção adicional. Certamente, não podemos nos satisfazer imaginando a procriação nos termos da vida que ela cria, se tomarmos a vida no sentido inglês, que exclui a morte. Ao menos, ambas podem ser unidas. Jolly (2001:180) escreve sem rodeios sobre os oradores Sa em South Pentecost: "apesar de os construtos ocidentais tenderem a polarizar nascimento e morte, criação e assassinato, as noções indígenas os percebem [...] como fases conectadas, em um processo cósmico de regeneração". E parece haver uma potência nos atos de corte e separação, aos quais poderíamos querer adicionar conotações sexuais. Como os temores e as expectativas kaulong tornam explícito, o discurso da Melanésia antiga frequentemente enunciava ambos juntos. Períodos de abstinência eram, portanto, críticos para a maioria dos atos de criação e destruição dos Sa. A abstenção impunha tanto proibições alimentares (inhame, taro) como a interdição das relações sexuais: a evitação era observada não apenas "para produzir desejo", mas também "para gerar a fecundidade humana e cósmica" em termos de "vitalidade, fertilidade e saúde" (2001:178, 184). Mais extensamente, seja através das gerações ou por meio de diferentes fases da vida social e ritual, a ativação de relações de gênero cruzado era intermitente.

Tubérculos e cormos têm seus próprios ciclos intermitentes de existência. Aparentemente, as pessoas fazem das plantas que propagam o que fazem de si mesmas: há diversas formas de se estar vivo ou morto. Na medida em que vida e morte são aqui tornadas equívocas, recomeçamos, novamente, o ciclo da descrição antropológica.

Recebido em 06 de janeiro de 2021

Aprovado em 14 de abril de 2021 


\section{Agradecimentos}

Partes deste texto se beneficiaram, em 2017, das críticas de colegas na Panteion University e na Free University of Brussels; em 2018, de colegas em Berkeley (Califórnia) e em Cambridge (Reino Unido - Conferência ESfO), aos quais agradeço muito. Uma visita à Papua Nova Guiné em 2015 foi possível graças à generosidade de um Emeritus Fellowship do Leverhulme Trust e ao contínuo interesse de amigos e conhecidos em Mount Hagen. O artigo foi reescrito, à luz dos materiais amazônicos, sob os auspícios do projeto de pesquisa da Fundação Internacional Balzan, Time and ethnographic horizon in moments of crisis (Centre for Pacific Studies, University of St Andrews). Não posso expressar o quão grata sou a Virgínia Amaral, Françoise BarbiraFreedman, Carlos Fausto e Stephen Hugh-Jones por me abastecerem com livros, artigos e ideias. Pelo estímulo especial, devo também agradecer a Tony Crook e Bruno Guimarães.

Marilyn Strathern é Professora Emérita de Antropologia Social da Universidade de Cambridge (Reino Unido). Sua carreira como pesquisadora começou com trabalhos sobre parentesco e relações de gênero, com ênfase na Melanésia, e ela é mais bem conhecida por sua obra O Gênero da Dádiva (1988; publicado no Brasil em 2006). Desde então, ela conduziu pesquisas antropológicas sobre concepção assistida, propriedade intelectual, culturas de auditoria e interdisciplinaridade. Recentemente publicado, Before and after gender (2016) foi originalmente escrito no início da década de 1970; uma nova incursão no tema do parentesco euro-americano é desenvolvida em Relations: an anthropological account (2020).

https://orcid.org/0000-0003-2004-1902

E-mail: ms10026@cam.ac.uk

Tradução: Bruno Nogueira Guimarães 


\section{Notas}

1 Explicitamente conectado ao habitat oculto dos espíritos baloma (Mosko 2017:263)

2 Uma vida de alimentação (nutrição) afetando a forma corporal flui das relações paternas. Os elementos maternos do corpo são conservados através dos enterros no território do subclã.

3 Um homem pode estar presente, mas não ocupa a mesma posição que as irmãs do pai. Os parentes paternos são mulheres para essa atividade; homens no lado paterno possuem outras atividades, assim como homens e mulheres do subclã materno da falecida são encarregados de diversos atos funerários.

4 O corte é atingido através de trocas mortuárias que, nos termos de Battaglia para os Sabarl (1983), cancelam as dívidas de quem morreu. Mosko (2017:236-7) elucida o uso do verbo "cortar", em relatos de outros lugares, tratando do rompimento dos laços na morte, e em sua própria tese (Mosko, 1983) sobre os rituais Mekeo em que, no desmembramento de uniões ancestrais, abrem-se caminhos para casamentos futuros.

5 E com a referência etnográfica específica aos Macuxi; ver o contraste com as considerações sobre o cultivo de mandioca pelos Huaorani (Rival 2002:89-90).

6 Nota do tradutor: neste texto, Strathern faz um uso deliberado da indiferenciação de gênero entre gerações, presentes tanto nos materiais etnográficos que ela mobiliza como em determinadas palavras da língua inglesa, a exemplo de parent e child. O português não possui um termo de uso rotineiro sem distinção de gênero que equivalha ao parent inglês - a opção por "pai" (ou "pais", no plural), além de levantar os problemas da desigualdade de gênero em uma suposta definição de "forma neutra" da língua, pode induzir quem lê a imaginar que se trata, exclusivamente, de uma figura do sexo masculino, causando confusão. Onde o sentido de parent era o de "genitor" (aquele que gera, não se limitando ao registro genealógico), esta foi a opção empregada na tradução. No caso de child, também para buscar um termo que se aproxime mais da ideia da autora, a opção foi por "criança" ao invés de "filho", compreendendo tanto a proposta de indistinção de gênero como a ideia de jovialidade pretendida por Strathern. Assim, esperamos que o par "genitorcriança" seja mais fiel à proposta da autora do que "pai-filho" ou "mãe-filha". Quando o sentido de parents não se limitava à noção de "genitores", como nos casos dos pais adotivos ou de criação, a opção foi pela tradução por "pais" ou "mães" (a depender da circunstância); estas situações também nos levaram a empregar "filhos" / "filhas" quando mais apropriado (a exemplo dos termos "sons" e "daughters").

7 Os primeiros sinais visíveis de técnicas de cultivo em Kuk, na área central das terras altas da Papua Nova Guiné, datam de 7000 a 6500 anos antes do presente, apesar de o desmatamento nas redondezas e as evidências de exploração vegetal remontarem a 10.000 anos atrás (Golson et al. 2017). Um horizonte de 9000-8000 anos é citado por Fausto e Neves (2018:1605) para as Américas. 
8 O cultivo melanésio inclui uma variedade de gramíneas e arbustos, entre eles alguns que oferecem hortaliças, leguminosas como o feijão alado, além de gengibre e pandanus. O sagu é de especial importância nas terras baixas.

9 Nota do Tradutor: isto é, levar em consideração a diferença de gênero dos parentes na geração ascendente, como no exemplo do funeral trobriandês em que mulheres da linha paterna podiam carregar a menina morta sem os riscos que o cadáver colocava às mulheres da linha materna (incluindo a mãe).

10 Nota do tradutor: "owner" [dono, proprietário], como outros termos em inglês empregados pela autora na construção de seu argumento, não distingue gênero. Assim, a escolha entre empregar "pai da roça" / "mãe da roça" [garden father / garden mother] ou "dono da roça" [garden owner] se torna uma escolha entre marcar ou não marcar a distinção de gênero.

11 As questões analíticas em que minhas considerações se concentram precisaram ignorar muitas outras, e isto se nota em sua incompletude etnográfica. No momento em que Rival escrevia o artigo a que me refiro, McCallum (2001), por exemplo, estava publicando seu estudo completo, Gender and Sociality in Amazonia.

12 Miller (2019:160-161) ouviu que a colheita é similar à morte para a plantação, exceto para aquelas sementes e talos separados para serem replantados, no idioma de serem "mantidos vivos".

13 Minha formulação para a implicação de que a relação mãe-criança não é apenas de identidade. "O que é atualizado cada vez que uma planta produz raízes, parece, é o potencial para um futuro sexual fecundo" (Rival 2001:75). Retornarei a isto posteriormente.

14 "Não apenas a capacidade de gestar crianças raízes é ativada no talo pelo princípio masculino (semente, sêmen, osso, luz solar) que ele contém, como ela também está ligada ao fato de que a mandioca doméstica origina do corpo de uma moça menstruando pela primeira vez" (Rival 2001:76). Se os talos aparecem sexualmente férteis - detectados na presença tanto de elementos masculinos e femininos - ao mesmo tempo eles são produtivamente femininos (em termos de gestação) em oposição à forma de reprodução masculina das mandiocas autossemeadas que não gestam raízes (2001:71). A ênfase aqui contribui para a discussão dela sobre as referências à clonagem assexual, abordadas mais tarde.

15 Parceiros sexuais e matrimoniais aparentemente abrangem sua própria forma de sedução; isto é particularmente observável no estrato superior, pois "na vida póstuma, há casamento, mas não procriação" (2017:213). Maizza enfatiza as implicações dos conceitos jarawara para as fusões euro-americanas de paternidade/ maternidade, conjugalidade, sexo e seus respectivos estereótipos.

16 E não pelos mestres dos espíritos; a frase aponta para a eventual falta de diferenciação entre almas humanas e vegetais uma vez que estejam livres de seus corpos. 
17 Estando tão novas, as almas-planta não precisam de muita persuasão para deixarem seus corpos (as almas das pessoas mortas são outra questão), mas serem persuadíveis é vital.

18 Infiro que a referência seja aos tubérculos postos de lado para serem replantados. A terminologia inglesa da semente, como em "semente de inhame" [seed yam], é confusa nesse contexto, e a evito.

19 Como a batata doce, regenerada a partir de ramas que lembram trepadeiras, a mandioca é uma cultura relativamente nova (ambas são introduções pré-coloniais). Cultivos alimentares melanésios não são rotineiramente atribuídos a espíritos nomeados, mas esta pode muito bem ser uma das formas em que a natureza especial do inhame ou do taro é marcada.

20 "Filhas e filhos" são concebidos de maneira tão variada quanto "mães e pais" o são; desnecessário dizer que as terminologias de gênero abrem outro conjunto de qualificações, não explorado aqui.

21 O material de Malinowski (1935a, 1935b) foi retrabalhado ou modificado etnograficamente inúmeras vezes, incluindo a natureza das inferências realizadas a partir da linguagem empregada. A etnografia de Mosko inclui um desafio sobre as dádivas da colheita. Um filho cultiva especificamente para o seu pai e parte de seus inhames é para ele; um homem recebendo tais inhames através da troca de dons se torna o "pai adotivo" dos frutos (tubérculos), sendo esperado que ele retorne itens de riqueza masculina concebidos como os frutos dos tubérculos que recebeu. Por sua vez, "esse item de riqueza masculina se torna a criança adotiva do homem que o recebe, que, como um fruto, ele pode converter em mais vias de trocas de dons" (Mosko 2009:689).

22 O inhame também é plantado com um pouco do "'velho talo' com o qual o tubérculo se ligava à sua planta mãe" (Malinowski 1935b:98), sua base ou raiz (Mosko 2009:682), de onde os trobriandeses contemporâneos dizem que o novo crescimento advém. Segundo Mosko, e não Malinowski, a superfície cortada do taro, de onde as raízes crescerão, se torna suas nádegas e pernas (procriadoras), ou base. (Os membros inferiores, incluindo os genitais, constituem as bases corporais da pessoa, com seu "olho" potencialmente procriador).

23 Não contabilizei o grande número de vezes que os etnógrafos da Melanésia e da Amazônia comentaram sobre a ativa apreciação das pessoas por novas variedades de cultivares.

24 Histórias de origem de "grupos de parentesco cognático ancestralmente localizados" imaginam um par de irmãos de sexo cruzado em seu ápice ou filhos de sexo cruzado de um fundador proeminente; os descendentes se dividem entre aqueles que vêm do irmão e os que vêm da irmã (Goodale 1995:180). Independente de onde vivam os seus membros, um conjunto de irmãos é associado a uma aldeia ou vila permanente, que perpetua a identidade do grupo. Sendo um substituto para qualquer genitor, uma criança pode - e muitas vezes não sem conflito - se filiar à posição da mãe ou do pai. 
25 "Jovens frequentemente repetiam a frase 'sou muito jovem para me casar e morrer'. Ou diziam: 'quando eu estiver velho e pronto para morrer, me casarei e encontrarei um substituto para mim, que me enterrará" (Goodale 1980:133). A contaminação pelas mulheres era um receio especialmente masculino.

26 A comparação de Rohatynskyj's (1990) é com os sistemas dos grupos de descendência lineares, que se voltam ao gênero do genitor. Isto posto, a "residência patrilocal" ömie implica as moças não percebendo sua filiação da mesma maneira que os rapazes: a "reciclagem dos homens, através do crescimento deles como [...] [espíritos] no interior do solo ancestral para emergirem como as encarnações de seus avôs, contrasta com o crescimento das mulheres [...] que são nutridas na superfície das terras de seus pais e maridos" (2004:93).

27 As pessoas compartilhando um emblema vegetal e ancestrais associados correspondem a um grupo local.

28 Nota do Tradutor: Calau [hornbill] designa uma família de pássaros presentes na Melanésia e em determinadas regiões da Ásia e da África. Os calaus mencionados pela autora provavelmente são os Rhyticeros plicatus, chamados, em inglês, de Papuan Hornbill ou Blyth's Hornbill, comuns na região habitada pelos Ömie.

29 Que a fórmula pareça familiar por conta de outras terminologias, como as terminologias de gênero e de regras de casamento recorrentes (ver Rio 2007; também notado por Rohatynskyj), sugere que a especificidade do sexo é particularmente esclarecedora da geração (intermediária) de genitores. Rohatynskyj (1990:97) aponta as limitações de uma fórmula antiga minha.

30 No inglês, "sett": um "termo botânico definindo o tubérculo, ou fragmento do tubérculo, replantado para se produzir uma nova planta" (Coupaye 2013:41), é usado para qualquer material vegetal regenerado sem semeadura. Relacionado a "assento" ["seat"] (algo posicionado), sett é etimologicamente distinguível de "conjunto" ["set"], como em "seita" ["sect"] (um grupo de entidades), mas o uso comum aproxima ambos. A discussão de Goodale sobre os irmãos kaulong em termos de conjuntos ["sets"] tem sido pouco observada, apesar de, como veremos, não haver equivalência simples entre eles.

31 Partindo de um englobamento simples de gênero como um tema de relações masculino-femininas, um exercício antigo de modelagem enfocou as conotações das relações entre gêneros cruzados (masculino e feminino) e mesmo gênero (completamente masculino, completamente feminino) (Strathern 1988:1834). Originalmente, usei os termos "sexo cruzado [oposto]" e "mesmo sexo", uma formulação que ecoava os descritores dos termos de parentesco; para os presentes propósitos, "sexo" pode ser confuso, então, onde esses conceitos são empregados, reapresento-os como "mesmo gênero" e "gênero cruzado". O modelo de gênero informa as considerações de McCallum (2001) sobre a socialidade kaxinawá e pode ser encontrado em um comentário melanesiano sobre os Achuar descritos por Descola (Strathern 2019b).

32 De fato, ela sugere que as "relações assexuais entre irmãos (tanto paralelos como cruzados) [oferecem] [...] modelos pata o gênero masculino e feminino" (Goodale 1995:158). 
33 A etimologia não ajuda neste caso (em contraste com a nota 26). Se tomarmos a procriação no sentido de gerar ou produzir descendentes, ou trazê-los ao mundo, tanto irmãos quanto cônjuges podem indicar descendência entre os Kaulong.

34 O florescimento infantil depende invariavelmente do fluxo de nutrição e riqueza; em Hagen, um pai dar riqueza aos parentes maternos da criança o esgota, na medida em que a criança floresce.

35 O termo inglês "geração" se refere tanto à reprodução / procriação como ao sequenciamento sucessivo de seres ao longo do tempo; torço para que o contexto distinga os usos. Distinguir as gerações como "genitores-crianças" não significa supor que os atores relevantes são o casal conjugal e sua prole; metades com funções procriadoras especializadas podem ser pareadas como sênior-júnior ou velha-jovem (Moutou 2013).

$36 \mathrm{Na}$ forma com que o cuidado paterno, por exemplo, é devolvido à sua fonte para reaparecer em outros momentos e lugares, ou com que um novo inhame emerge de um solo recentemente preparado, no lugar de um inhame antigo. Em muitas situações, tais substituições são apenas completamente percebidas quando suas capacidades regeneradoras são tornadas evidentes.

37 "Pois assim que um homem se torna um jaguar, o jaguar não está mais ali" (Viveiros de Castro 2010:237).

38 Como na não equivalência das relações de afinidade e de outras relações em que genitores e crianças estão imersos, cada geração sendo plantada em solo jovem ou em novos espaços de roças.

39 (Antes, é arrelacional, um ponto que ela desenvolve em uma discussão sobre a socialidade jívaro.) Minha observação é sublinhada pela maneira com que relações assexuais aparecem em outro contexto, quando ela escreve sobre irmãos de sexo cruzado sendo pareados em uma "prefiguração sem sexo da relação conjugal" (Taylor 2001:47).

40 A atenção de horticultores e especialistas rituais não é, de modo algum, restrita ao momento de que trato; sobre plantações que não poderiam crescer sem magia, ver, classicamente, Malinowski (1935a, 1935b).

41 O corte procriador cria uma divisão entre a planta e o cultivador, e entre a potencialidade da planta e sua realização. Enquanto os homens abelam que plantam as raízes de tubérculos se referem a elas como "mãe" ou "placenta" das plantas que virão, por conta de suas próprias atividades alimentando os tubérculos subterrâneos, eles chamam a si mesmos de "pais" (Coupaye 2013:40-41). A relação de gênero cruzado parece apontar na direção dos diferentes papéis de cuidado em relação às plantas jovens. (Foram os Abelam que levaram uma etnógrafa, no passado, a falar do falo como um órgão de nutrição [Strathern 1988:126]). O ponto é que, mesmo quando o ritual tem explícitas referências à atividade sexual e aos órgãos da cópula (ver, para South Pentecost, Jolly 2001:185), tal conjunção não é a única fonte da agência procriadora. 
42 Em relação aos trobriandeses e às conotações ancestrais das irmãs do pai que carregam o cadáver, uma pessoa pode ser literalmente absorvida pela outra.

43 Extremas, mas não únicas: ver Lattas (2000:135) sobre os Baining, também em New Britain, onde "a natureza permanente ou vitalícia dos casamentos baining sustentavam as práticas tradicionais de morte da viúva".

44 "O modelo é um em que um conjunto de irmãos cruzados reproduzem a si mesmos em cada geração subsequente [adjacente]" (Goodale 1995:180).

45 Um viúvo pode tentar se matar na ocasião da morte da esposa, mas os homens também podiam ter casamentos polígamos, e a morte não era automática como era para a esposa.

46 Em uma ocasião, em 1959, a tarefa sobrou para um filho, que se lembrou: "quando hesitei, minha mãe se levantou e falou em voz alta, para que todos ouvissem, que a razão pela qual eu hesitava era porque eu queria ter sexo com ela - ela me envergonhou" (Goodale 1995:176).

47 Dois irmãos estavam geralmente envolvidos. "A principal obrigação de um homem com os filhos de sua irmã deriva de sua obrigação de estrangulá-la quando da morte do marido desta, para que ela possa ser enterrada com ele" (Goodale 1995:176). No período de seu subsequente trabalho de campo, os irmãos se apressavam a ficar ao lado da irmã quando escutavam que ela enviuvara, prevenindo-a de cometer suicídio por vergonha. A causa da vergonha seria a insinuação de que, caso não morresse, ela se tornaria sexualmente ativa após o falecimento do marido. 


\section{Referências bibliográficas}

BAMFORD, Sandra. 1998. "Humanized landscapes, embodied worlds: Land use and the construction of intergenerational sociality among the Kamea people of Papua New Guinea". Social Analysis, 42 (3):2854.

BATTAGLIA, Debbora. 1983. "Syndromes of ceremonial exchange in the eastern Calvados: The view from Sabarl Island". In: J. Leach \& E. R. Leach (eds.), The kula: New perspectives on Massim exchange. Cambridge: Cambridge University Press.

BONNEMĖRE, Pascale. 1998. "Trees and people: Some vital links. Tree products and other agents in the life cycle of the Ankave-Anga of Papua New Guinea". In: L. Rival (ed.), The social life of trees: Anthropological perspectives on tree symbolism. Oxford: Berg. pp. 113-131.

BUTLER, Judith. 2000. Antigone's claim: Kinship between life and death. New York: Columbia University Press.

BUTLER, Judith \& ATHANASIOU, Athena. 2013. Dispossession: The performative in the political. Cambridge: Polity Press.

CARNEIRO DA CUNHA, Manuela. 2019. "Antidomestication in the Amazon: Swidden and its foe". HAU, Journal of Ethnographic Theory, 9 (1):126-136.

COUPAYE, Ludovic. 2013. Growing artefacts, displaying relationships: Yams, art and technology amongst the Nyamikum Abelam of Papua New Guinea. Oxford: Berghahn.

DENHAM, Tim. 2017. "Domesticatory relationships in the New Guinea Highlands". In: J. Golson et al., Ten thousand years of cultivation at Kuk swamp in the Highlands of Papua New Guinea (Terra Australis 46).
Canberra: The Australian National University/ ANU Press. pp. 39-49. DESCOLA, Philippe. 1994 [1986]. In the society of nature: A native ecology in Amazonia. Trans. by Nora Scott. Cambridge: Editions de la Maison des Sciences de l'Homme/ Cambridge University Press.

FAUSTO, Carlos \& NEVES, Eduardo G. 2018. "Was there ever a Neolithic in the Neotropics? Plant familiarisation and biodiversity on the Amazon". Antiquity, 92 (366):1604-1618.

GOLSON, Jack; DENHAM, Tim; HUGHES, Philip; SWADLING, Pamela \& MUKE, John (eds.). 2017. Ten thousand years of cultivation at Kuk swamp in the Highlands of Papua New Guinea (Terra Australis 46). Canberra: The Australian National University/ ANU Press.

GOODALE, Jane C. 1980. "Gender, sexuality and marriage: A Kaulong model of nature and culture". In: C. P. MacCormack \& M. Strathern (eds.), Nature, culture and gender. Cambridge: Cambridge University Press. pp. 119-142.

. 1995. To sing with pigs is human: The concept of person in Papua New Guinea. Seattle: University of Washington Press.

JOLLY, Margaret. 2001. "Damming the rivers of milk? Fertility, sexuality, and modernity in Melanesia and Amazonia". In: T. Gregor \& D. Tuzin (eds.), Gender in Amazonia and Melanesia: An exploration of the comparative method. Berkeley: University of California Press. pp. 175-206.

LATTAS, Andrew. 2020. "Re-analysing the Baining: The mytho-poetics of race, gender and art". Oceania, 90 (2):98-150. 
LEPANI, Katherine. 2012. Islands of love, islands of risk: Culture and HIV in the Trobriands. Nashville: Vanderbilt University Press.

MCCALLUM, Cecilia. 2001. Gender and sociality in Amazonia: How real people are made. Oxford: Berg.

MAIZZA, Fabiana. 2017. "Persuasive kinship: Human-plant relations in Southwest Amazonia". Tipití: Journal of the Society for the Anthropology of Lowland South America, 15 (2):206220.

MALINOWSKI, Bronislaw. 1935a. Coral Gardens and their magic: A study of the methods of tilling the soil and of agricultural rites in the Trobriand Islands. Vol. I. London: George Allen \& Unwin Ltd. . 1935b. Coral Gardens and their magic: A study of the methods of tilling the soil and of agricultural rites in the Trobriand Islands. Vol. II. London: George Allen \& Unwin Ltd.

MILLER, Theresa L. 2019. Plant kin: A multispecies ethnography in indigenous Brazil. Austin: University of Texas Press.

MOSKO, Mark. 1983. "Conception, deconception and social structure in North Mekeo culture". Mankind, 14 (1):24-32 .

. 2009. "The fractal yam: Botanical imagery and human agency in the Trobriands". JRAI (n.s.), 15 (4):679700.

MOSKO, Mark (with Tabalu Pulayasi Daniel, Molubabeba Daniel, Pakalaki Tokulupai \& Yogaru Vincent). 2017. Ways of Baloma: Rethinking magic and kinship from the Trobriands. Chicago: University of Chicago Press/ HAU Books.

MOUTU, Andrew. 2013. Names are thicker than blood: Kinship and ownership amongst the Iatmul. Oxford: OUP for The British Academy. RIO, Knut. 2007. The power of perspective:
Social ontology and agency on Ambrym Island, Vanuatu. Oxford: Berghahn Books.

RIVAL, Laura. 1998. "Trees, from symbols of life and regeneration to political artefacts". In: L. Rival (ed.), The social life of trees: Anthropological perspectives on tree symbolism. Oxford: Berg. pp. 1-36.

. 2001. "Seed and clone: The symbolic and social significance of bitter manioc cultivation". In: L. Rival \& N. Whitehead (eds.), Beyond the visible and the material: The Amerindianisation of society in the work of Peter Rivière. Oxford: Oxford University Press. pp. 57-79.

. 2002. Trekking through history: The Huaorani of Amazonian Ecuador. New York: Columbia University Press.

ROHATYNSKYJ, Marta A. 1990. "The larger context of Ömie sex affiliation". Man, Journal of Royal Anthopological Institute, 25 (3):434-453.

. 2004. "Ujawe: The ritual transformation of sons and mothers". In: P. Bonnemère (ed.), Women as unseen characters: Male ritual in Papua New Guinea. Philadelphia: University of Pennsylvania Press. pp. 75-97.

SCHNEIDER, Almut. 2017. La Vie qui Vient d'Ailleurs: Mouvements, Echanges et Rituels dans les HautesTerres de la Papouasie-NouvelleGuinée. New York : Lit Verlag.

STRATHERN, Marilyn. 1988. The Gender of the Gift: Problems with women and problems with society in Melanesia. Berkeley and Los Angeles: California University Press. . 2017. "Gathered fields: A tale about rhizomes". ANUAC, 6 (2):271-292. . 2019a. "A clash of ontologies? Time, law and science in Papua New Guinea". HAU, Journal of Ethnographic Theory, 9 (1):58-74. 
. 2019b. "Generating plants and people". In: G. Cometti ; P. Le Roux ; T. Manicon \& N. Martin (eds.), Au seuil de la foret: Hommage a Philippe Descola, l'anthropologue de la nature. Paris: Tautem. pp. 1019-1027.

TAYLOR, Anne-Christine. 2001. "Wives, pets and affines: Mariage among the Jivarao". In: L. Rival \& N. Whitehead (eds.), Beyond the visible and the material: The Amerindianisation of society in the work of Peter Rivière. Oxford: Oxford University Press. pp. $45-56$.

VIVEIROS DE CASTRO, Eduardo. 2010 [2007]. "Intensive filiation and demonic alliance". In: C. B. Jensen \& K. Rödje (eds.), Deleuzian intersections: Science, technology, anthropology. Oxford: Berghahn Books. pp. 219-253.

YAMAJI, Katsuhiko. 1994. "Plant and gender: The reproductive image of mother in the Nakanai of Papua New Guinea". In: K. Yamaji (ed.), Gender and fertility in Melanesia. Nishinomiya: Kwansei Gakuin University Press. pp. 13-46. 
REGENERAÇÃO VEGETATIVA:

UM ENSAIO SOBRE

RELAÇÕES DE GÊNERO

\section{Resumo}

As diversas formas com que antropólogos da Amazônia e da Melanésia empregaram termos genéricos, como genitores e crianças, levam a uma exploração dos momentos em que a distinção de gênero pode não ser colocada em primeiro plano. Certos aspectos da vida cultivada das plantas, como no caso das principais culturas alimentares e da reprodução vegetativa comumente atribuída a elas, acabam nos oferecendo novas possibilidades expositivas. Considerando que a maior parte da análise é apresentada "por meio de" (um pequeno número de) iluminações etnográficas de ambas as regiões, a autora também se permite algumas formulações no lado melanésio. Palavras-chave: Amazônia, Melanésia, Cultivares, Relações de gênero, Vida vegetal, Procriação, Morte, Parentesco, Clonagem.
VEGETATIVE REGENERATION: AN ESSAY ON GENDER RELATIONS

\section{Abstract}

The diversity of ways in which anthropologists of Amazonia and Melanesia have deployed the generic terms "parent" and "child" prompts an exploration of moments where gender distinctiveness may or may not be foregrounded. Certain aspects of the life of cultivated plants, in this case people's principal food crops, and the vegetative reproduction commonly attributed to them, turn out to offer fresh expositional possibilities. Whereas much of the analysis is presented "through" (a small number of) ethnographic illuminations, on the Melanesian side the author also allows herself some speculative formulations.

Keywords: Amazonia, Melanesia, Cultivars, Gender relations, Plant life, Procreation, Death, Kinship, Cloning. 


\section{REGENERACIÓN VEGETATIVA: \\ UN ENSAYO SOBRE \\ RELACIONES DE GÉNERO}

\section{Resumen}

Los diversos modos con los que antropólogos del Amazonas y de Melanesia emplean términos genéricos, como por ejemplo "genitores" y "crianças", invitan a indagar en aquellos momentos en que la distinción de género puede no ser colocada en primer plano. Ciertos aspectos de la vida cultivada de las plantas, como aquellos que atañen a las principales culturas alimentarias y a la reproducción vegetativa que comúnmente se atribuye a estos seres, nos ofrecen nuevas posibilidades expositivas. Considerando que la mayor parte del análisis es presentada a través de un pequeño número de iluminaciones etnográficas realizadas en las dos regiones contempladas en la investigación, la autora también se permite algunas formulaciones respecto del lado melanesio.

Palabras clave: Amazonia, Melanesia, cultivos, relaciones de género, vida vegetal, procreación, muerte, parentesco, clonación. 